a committee to be stimulating to the verge of exultation.... I am sure you will find, as I have, that committee work (while it does take some time away from other creative pursuits) is exactly the stone to keep a keen edge on one's intellectual razor."

As might be expected, Mike Valinis of the Ohio State University Libraries has frequently used his sharp wit to reveal in News Nosey the true nature of committee work there. The Turkey Week 1988 issue, for example, announced the formation of a Search Committee Department to "relieve the faculties and staff of present duties and free up time for all the other committees and task forces on which they should be serving." His best effort, however, came in the April 1, 1984, issue where, under the apt heading, "Another New Committee," he revealed that: "The Liberry administration has announced the formation of a new committee, the Rubber Stamp Committee, which will meet on a regular basis to give formal approval to any of the administration's decisions, thus foregoing the need for contentious and time-consuming task forces. Members have yet to be announced." Just as staff are wary of committees, though, so are administrators. In his advice to an associate leaving to become a library director elsewhere, Jay Lucker, in the July 1989 issue of the MIT Libraries Notes, spoke to the matter. He cautioned her to "avoid the temptation to appoint committees. They have a life of their own and will come and go without any intervention on your part."

Despite our cynical attitude and our gentle, or not so gentle, carping, committees remain at the heart of the academic library's accepted mode of operation. We couldn't do without them so we are fortunate that they can inadvertently give us so much pleasure as prime targets for our humor.

\title{
Sailing the seas of information at Cleveland State
}

\section{By Billie Reinhart}

\author{
Coordinator of Bibliographic Instruction \\ Cleveland State University
}

\section{and Gary Thompson}

\author{
Hecid of Information Services \\ Cleveland State University
}

Library orientation followed a little different approach this year at Cleveland State University. In July, the dean of student life met with the director of the library, the head of information services, and the coordinator of bibliographic instruction, to explain that the Student Life Department had designed a new format for the university orientation of incoming students this year, with less emphasis on the traditional informational talks and more emphasis upon student participation. Students were divided into teams and given points for events throughout the day. The orientation had a nautical theme after the school team, the Vikings. Two separate orientations took place, first in late August for over two hundred students, and the second in mid-September for over four hundred.

For its part of the orientation, the library designed an event that would be both fun and a learning experience. In previous years librarians had given fifteen-minute talks about the library collection and services to groups of twenty-five to thirty students in classrooms away from the library. This year the students were brought to the library on two separate days for forty-five minute orientation periods. The Bibliographic Instruction Team decided that the orientation would combine the nautical theme with the new trend toward information literacy, and thus came up with the theme, "Sailing the Seas of Information at the CSU Library." Instead of lectures, the team integrated two different approaches to library instructionnamely, the self-guided tour and the use of cue cards. The latter idea was publicized recently in the library literature. ${ }^{1}$ Students moved around the library to visit different "ports," each of which had a large cue card to explain the function of that area of the library, the reference center, the new book section, the author/title catalog, the subject catalog, the general periodical indexes (Infotrac and Readers' Guide), and the reserve and circulation desks. Incidentally, two weeks after the orientation, the card catalog was replaced by Scholar, the new online public access catalog based on the NOTIS System.

The logistics for moving one hundred to two hundred students smoothly through nine ports in forty-five minutes took lots of imagination and creativity. The BI team designed a "Passport to

'Bethany Lawton and Ann Pederson, "Cue Card Clues: A New Approach to Library Orientation," Research Strategies 6 (Spring 1988): 77-79. 


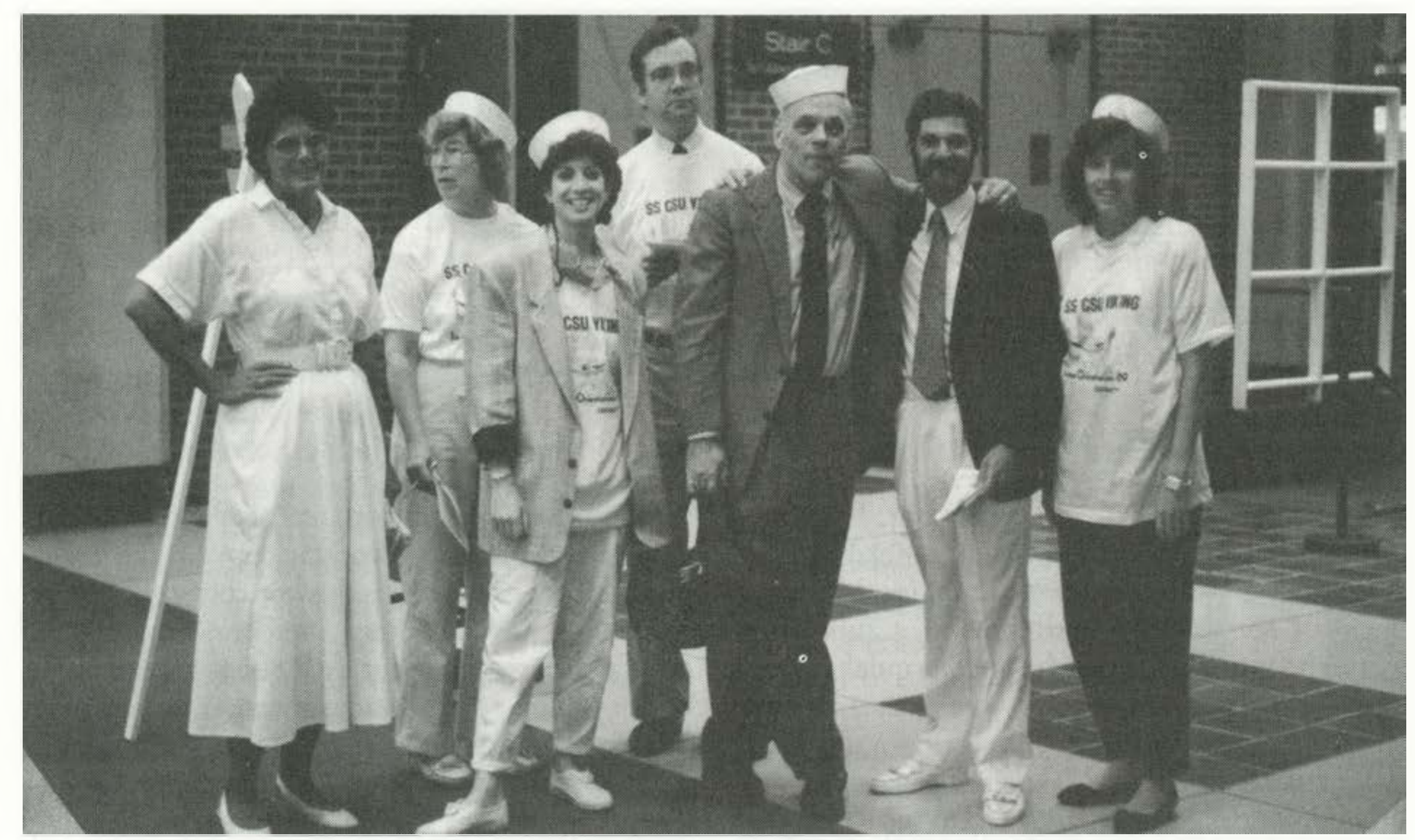

Left to right: Billie Reinhart, Virginia Keel, Juanita Pichler, Gary Thompson, Philip Tramdack, George Lupone, and Barbara Trizzino.

Information," which listed the eight ports, gave a brief description of each, and instructed the students to look for various information at each port. On the back was a map of the library showing the locations of the "ports of call." The difficulty of the tasks varied from locating a book on a nautical theme on the new book shelves to finding an article on an assigned subject in a periodical index. Ten separate sets of questions were formulated and the passports were color-coded by set. This provided a variety of questions so that there were not too many students working on the same questions at the same time.

Upon entering the library each student was welcomed by library staff members (dressed in sailing attire), given a port number, and sent on their way to an assigned port. On arrival at the port, the student was told to read the cue card and find the information requested on the passport. The information was checked by the staff member and, if the information was correct, the passport was stamped and the student told to proceed to the next port. When finished with the assigned ports, nearly every student elected to complete the bonus questions, an indication of the high interest in the process and the team effort. The student teams earned points for every stamp on their passports, which contributed toward a prize at the end of the day.

The reaction from the freshmen was enthusiastic, but the most positive feedback came from the student counselors for each team. The counselors said over and over again that this was so much better than their own experience with freshmen orientation. In fact, the new students indicated with enthusiasm that the library component was by far the most interesting and positive experience for them during the two days of orientation. The library staff also got into the spirit of the event with nautical attire and much enthusiasm.

This was very much a cooperative enterprise. The Bibliographic Instruction Team spent many hours in planning and preparing for the event, including designing the passport, the questions, the cue cards, and the bookmarks. On the dates of the orientations, twelve to fifteen staff members from all departments of the library volunteered to assist with the orientation exercise. All of this resulted in smooth sailing during the event.

The library orientation was very successful, through reaching some seven hundred students in four sessions, and through the wonderful response to the event from beginning students, upperclassmen, faculty, and administrators and through the excellent public relations and publicity for the library.

To top it off, the library staff participated in the student carnival that night with a booth where photographs of famous Clevelanders were shown to the new students who were asked to guess who the personalities were. It was fun to watch the students' faces as they struggled to identify the portraits of famous men and women from the recent and distant past. The most difficult photographs for the students to identify turned out to be those of Elliott Ness and Toni Morrison. 